\title{
Analysis and Apocalypse of Japanese Style Creation Aesthetics
}

\author{
Peng Xin-qin ${ }^{1, \mathrm{a}}$ \\ ${ }^{1}$ Visual dean, Art\&Design Department, Bengbu university, Anhui, China
}

\begin{abstract}
Japanese style design has a good reputation in the world design community. Its elegant details, metaphorical techniques, quiet and tranquil aesthetic style, and the simplest form of the natural true design concept are praised by the world. The analysis of its aesthetic characteristics can be of great inspiration to the reference and modern construction of Chinese product aesthetics.
\end{abstract}

\section{Introduction}

The modern design of Japan was established after World War II. It has been mature since 1953, and has taken a place in the contemporary world design. Analyzing its aesthetic characteristics can play a role in product design in modern China. At the same time, with the "jump frog strategy [1]", combined with China's rich social and a long traditional culture, it can effectively promote the integration of Chinese design resources and economic takeoff.

\section{Aesthetic is the Experience Construction of the Subject and Object}

Aesthetics are a construction activity ${ }^{[2]}$, and it is the process of the aesthetic object being constructed by the imagination of the aesthetic subject. In this process, the main body constructs psychological facts and inner images. The two sides through the "isomorphism", as the object of the beauty of the form of the body through the psychological structure of the body, when the two "homomorphism", beauty can be displayed on the object. This kind of aesthetic is relative and dynamic. With the increasingly rich nature of human strength and psychological structure, the relationship between human and reality is expanding. This aesthetic activity is the interaction and construction process of the interaction between subject and object. This construction is a twoway process. It also constructs the object world while constructing the main body's aesthetic psychological structure $^{[3]}$.

Aesthetics comes from a need, a fifth level need, that is, the need for order, harmony and beauty.

According to the latest Maslow needs theory, the needs is divided into six levels: one for biological needs (Physiological needs), that is to meet the biological needs of human beings; the second is the security needs (Safety needs), including safety, life stability, and freedom from suffering, threat or disease; and third, love and belonging. The needs (Love and belonging), such as: friendship, love and affiliation needs. Fourth is the need for respect (Esteem), and the need for respect can be divided into three categories: self-esteem, respect for others and power desires, including self respect, self evaluation and respect for others; the fifth is the need for experience and cognition (Experience purpose, meaning and realizing), that is, the cognition and sense of intrinsic potential. The sixth is self actualization need. that is, to develop its potential to achieve its own development needs ${ }^{[4]}$. As shown in Figure 1. As far as design aesthetics is concerned, the theory of needs is actually aimed at the aesthetic subject, and it is actually a construction process completed by means of aesthetic objects.

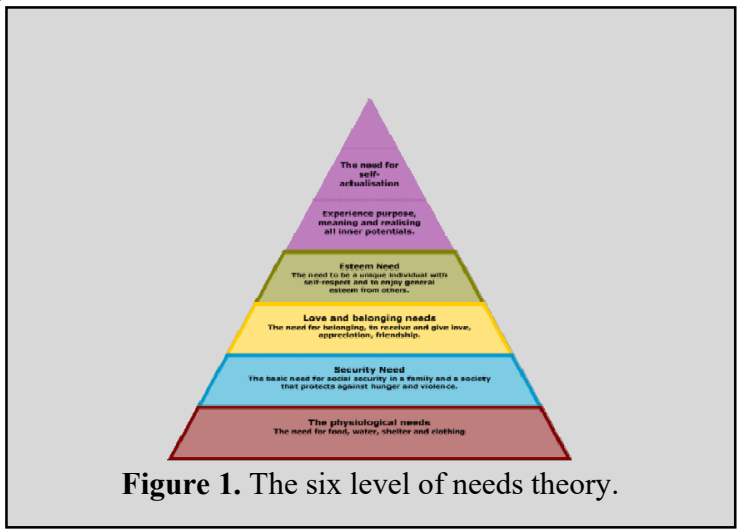

\section{Analysis of Japanese Creation Aesthetics}

Japanese contemporary aesthetics of creation are mainly embodied in the works of some excellent design products and designers. Japanese style creation, aesthetics are mainly embodied in two aspects in the field of product design. First, its traditional Zen aesthetics embody the design and modern design of Japanese traditional utensils. Second, its contemporary simplicity and light and short wind are embodied in the design of modern products, especially in the design of electronic products and transportation tools. Among

*Corresponding author: ${ }^{\text {a } 46098831 @ q q . c o m}$ 
them, the most representative is Japanese industrial design, such as WUJI design and main designer, such as the original design practice of Kenya Hara. The following two aspects are analyzed.

\subsection{An analysis of the aesthetic characteristics of traditional Japanese utensils}

Japan is a regional nation with a long history. The design of traditional utensils has experienced hundreds of years of history, and it has continued to survive and develop in Contemporary Japanese society. It is mainly embodied in the design of daily products, such as traditional furniture, porcelain, iron, tableware, lacquer ware and other living products. The traditional implement in Japan are mostly produced by traditional techniques, and are famous for their simple modeling and quiet aesthetic characteristics. For example, the lacquer of Wajima in Ishikawa County, as shown in Figure 2, Japanese lacquer is not only used to eat, but it inherits a long culture. In Japanese tradition, lacquer ware is the spirit of ceremonies and ceremonies.

At the same time, the atmosphere of festivals is brought into daily life. The design model of this dish is simple, highlighting the natural texture of the wood itself, without any superfluous ornaments, only the change and contrast of the size arc, the unifying of the lonely bowl, the color of the monochromatic class color paint, and the wood material used in the lacquer is made of the whole natural Rohan cypress or beech. And then planned by the plank division, the craft is exquisite. The wood embryo is thin enough to penetrate the wood embryo to see the other side. Finally, the lacquer made from the paint of the lacquer tree has been given the bright and beautiful luster. Therefore, in the use of material, this product is loyal to the nature of material and keeps the beauty of simplicity; in the use of color, the name of the local animals and plants is named, and the aesthetic feeling of Japanese naturalism is embodied; in the artistic expression, the logs are used to reduce the traces of the cave to be carved naturally. To hold the true position of life.

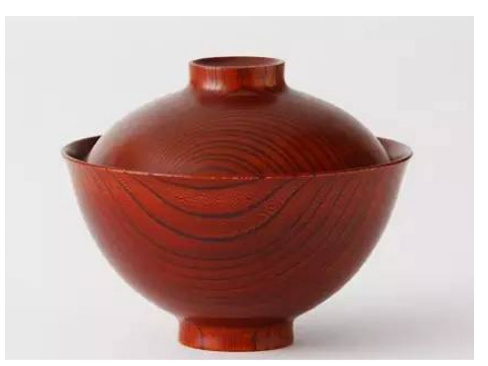

Figure 2. Lacquerware in Wajima, Ishikawa County.

Different from the cultural characteristics of the Chinese Confucianism and Taoism, Japan is the influence of the Buddhist culture of the single nation. The Buddhist Zen thought has formed a unique Japanese Zen thought since the introduction of India through China. It began in the Tang and Song dynasties in China, especially by the hands of the Kamakura Shogunate, the Chinese Zen. The aesthetics were introduced into Japan, and combined with the faith of the local deity quickly, which produced the greatest change and maturity of the
Japanese ontological philosophy, the birth of the Zen Aesthetics of Japan, the influence of the various fields of Japanese society, especially the traditional cultural form, and the combination of two with the long spirit of Bushido in Japan. The death is like a life and death view, and at the same time, it affects the Japanese martial arts people's attention to repair their minds and abandon their miscellaneous thoughts.

People usually refer to the Zen spirit of Japan by Wabi, Sabi and Shibui. Here, these three positions are used to describe their design aesthetics. "Wabi" means to be far away from the world and to live in a Zen forest. As far as the aesthetic of the utensils is concerned, it can refer to the simplicity and simplicity of the retreats, the unsatisfactory and irregular beauty of nature; the Sabi refers to the impermanence of Buddhism, and the things in the world are transient and vicissitudes, which are reflected in the utensils, mainly utensils. The beauty of some of the traces left over and the gloss of the "pulp" of the years, and the meaning of the beauty of incomplete; Shibu "astringent" means convergent, Unostentatious, or simple and elegant ${ }^{[5]}$.

\subsection{The beauty of modern Japanese product creation}

The modern Japanese product design is mainly characterized by miniaturization, convenience, versatility and detail oriented process. Due to the limited territory of Japan, to develop a developed economy in a limited territory, what we need is pioneering and wisdom. Therefore, the Japanese design, which shows obvious modernity characteristics, is mainly embodied in the full consideration of the relationship between high technology and environment, ecology and products, such as the concept of Kansei Engineering, electronic robot, automobile product and architectural design, which is famous for the sustainable design concept of technology and environmental protection. Therefore, we can also see the embodiment of Japanese design aesthetics in modern product design, focusing on the original ecology of the natural environment, the simple beauty of the human living environment and the beauty of morals that pay attention to the social environment.

For example, the design of MUJI is simple, simple and environmentally friendly. With the last element to restore the natural truth, with no consideration, the inner structure and the subtle features are implied in the external image, symbol, and the words have the best meaning, and the profound connotation is embodied in the extrinsic products.

This CD music player, see Figure 3, looks like an old-fashioned fan. When you pull down a rope, with a clack, 


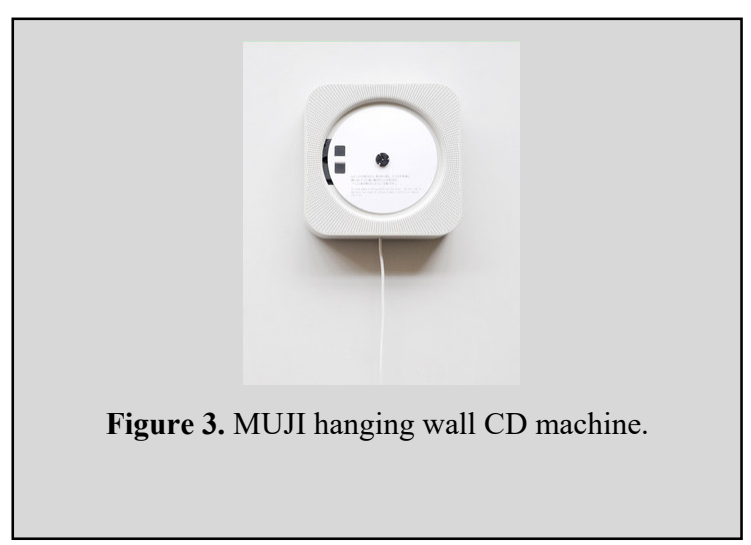

the CD player begins to play music, which seems to allow users to recall the happy hours of their childhood. Naoto Fukasawa, the designer of MUJI, expressed the most clean design interacts with the most concise abstract forms and simple colors. It expressed the essence of his intuition, design by undesigned technique, at the same time, the design details were also very thorough, and the limited few design elements were properly balanced. With the image of Zen Buddhism and aesthetic qualities.

There are many similar products, such as Japanese cars, compared with American cars, economic, oil saving, small space, simple materials, small pollution to the environment, and some famous Japanese design companies, such as TOYOTA, SONY, Panasonic, Canon, MITSUBISHI, Nikon, SANYO developed. FANUC is the most powerful enterprise in the production, design, manufacture and sales of professional CNC systems, accounting for $70 \%$ of the global market share. Under the premise of satisfying technology, we should consider people's aesthetic habits and aesthetic psychology. From the view of the world layout, Japan is a small island country. Under the boundless sea, it is easy to produce the psychological feelings of the people. It is a important geographical factor and the Humanistic Psychological factor in the Japanese philosophy. The Japanese industry is developed, the society is long in technology, and the Japanese are not ignored. The perceptual factor of human emotion is embodied in the aesthetic of product design, which is a kind of beauty, of silence, simplicity, irregularity and asymmetry, and the harmony between yin and Yang of the utensils. The design of MUJI embodies the philosophical and aesthetic features of "no plan" and "Yin Yang transformation". MUJI is "NO BRAND", and no brand is a big brand.

\section{Conclusion}

Japanese industrial design is realized by combining the excellent cultural traditions of our nation and western modern design ideas with the help of advanced scientific and technological research. In the development of modern economic and industrial design, we do not forget the excellent cultural heritage of the nation, and combine the spirit of God, the view of geographical resources and the design of modernity in the nation, thus forming a double track parallel product and aesthetic style of modern Japanese design. First, in the traditional utensils, the Japanese to the environment protection and cherish the achievement of their small and exquisite, simple and silent design of the wind. Second, in the modern product design, the Japanese Shibu design aesthetics emphasize the grim, order and elegance, Wabi claims the original, plain, both and the West. It is a combination of rationalism and design aesthetics, symbiotic with exquisite details, simple form metaphor and modular design beauty.

As far as the aesthetic subject is concerned, the designer, in shaping the product, has been well versed in the idiosyncratic characteristics of the Zen Aesthetics of Japan, and integrates it in the expression of product form, color, material and metaphor, thus constructing the aesthetic object. When the user is watching and using the product, the aesthetic object which is merged into the product can be used. The psychological structure of users' history and culture resonates, and beauty comes into being.

Compared with the single race and cultural tradition in Japan, China is rich in nature and rich in natural resources. This sense of superiority has caused the young generation of today's use of articles and the waste of living habits. In the field of product design, the design of sustainable system is not too much for the design of sustainable system. Social integration service design is currently on the agenda. We should carry forward the fine tradition of the Chinese Mohist's thrift and frugality rather than the decadent lifestyle of the poor and extravagant pursuit of Western hedonism, which is the trampling of the main personality and the great destruction of the self-agreement of the aesthetic subject. In the field of product design, the loss of respect for things, goods and design, although temporarily can be changed to a brilliant visual aesthetic effect, but this effect belongs to the privileged class and aristocracy, divorced from the people, is not long. In the long run, it makes the people lose respect for the utensils, ignore the natural essence of the objects, and eventually lose the aesthetic self-discipline of the aesthetic subject leading to the aesthetic deviation and the loss of human nature. The method is also a philosophical aesthetic thought contrary to the return of Chinese Taoism to nature. We should have the least respect for utensils, which is the first revelation of Japanese artifact aesthetics to contemporary Chinese product aesthetics.

On the second level, from the Japanese style Wabi and Shibu contemporary creation aesthetic style, Japanese aesthetics is based on the austere, detailed and modularized, and elegant aesthetic qualities, and the beauty of order and irregularity, the beauty of nature and the incompleteness of the imperfection.

The opposing factors are finally unified in the design of the noumenon. China's contemporary product design should also seek its own aesthetic design in the rush and unification. One is to take advantage of the advanced foreign technology and design experience to consider the rich and rich social resources and leap frog strategy to realize the leap forward development of industrial design and product aesthetics; the two, respect the excellent tradition of our nation, integrate the national aesthetics 
with the excellent design aesthetics of foreign countries, treat them equally and harmonization. And the method of feedback to achieve harmony and unity in "hedging", that is, the above impulse and unification.

In short, compared with Japanese contemporary aesthetics of creation and Chinese product design aesthetics, "harmony soul and talent ${ }^{[6] "}$ can be seen in the differences between China and Japan. This difference is the difference in economic development, the difference in design level and level, the difference of design method and manufacturing process, cultural difference, and the difference of design thinking and mode of operation. At the moment, China needs to adjust several directions to make the design business fly, and through the design of the aesthetic style of Chinese design and the erect position of the world design and national forest.

Firstly, we should quickly integrate the natural and social resources of China, adjust the design and manufacture mode, give order rectification to the design enterprises that destroy the natural environment; secondly, protect the traditional natural resources and develop biological and industrial technology, rather than simply promote the development of the design through the sale of goods and the virtual economy of the network. Thirdly, to improve the cultural connotation and aesthetic interest, to build a symbiotic environment between the aesthetic subject and the aesthetic object, to refine and develop the excellent heritage of the Confucianism, Taoism, and to reshape the unique aesthetic style of China's product design. Finally, the construction of excellent design education and the design of talent reserve mechanism requires the government, the society and the university education. The mechanism of cooperation and the vigorous reform of the teaching team are not overnight. At present, this reform can only be promoted by improving the excellent design talents and encouraging the creation of folk outstanding designers. For example, in the reform of design education in Colleges and universities, we can improve the situation by creating an atmosphere of respecting the excellent cultural heritage and refining the essence of Chinese cultural tradition in practice. We take the opportunity of improving traditional Chinese literature and art aesthetics and symbols. We take the opportunity of improving the main philosophy and aesthetics in history. The bad design education situation and the declining moral and ethical trend can be changed through the above efforts. Through the call of the design ethics and the design of the logical order, these two measures have buried the aesthetic style of the fine product design with Chinese characteristics in the future. As Xu Hengchun said in the book of design aesthetics, the creation of aesthetic value is on the one hand, on the other hand, on the basis of the molding of the human senses and psychology, only in the correspondence and Isomorphism of the two can people perceive the beauty of things ${ }^{[7]}$. From the analysis of aesthetic subject and guest relations, the aesthetic of product design is to build aesthetic objects through the first aesthetic subject (product stylist) with a certain medium, and then the aesthetic object is reacting on the second aesthetic subject (i.e. the user), if the second aesthetic subject is produced by some elements in the aesthetic object when watching or using the product. With aesthetic sympathy, beauty is presented. Therefore, this is an aesthetic process and an aesthetic context, mainly through the aesthetic subject to be fully highlighted, the aesthetic subject of wisdom, consciousness, cultural, psychological structure and aesthetic levels are particularly important, he is the key to determine whether the above four can be realized. Therefore, in this regard, it is the fundamental to cultivate excellent design talents with high comprehensive quality. The case of Japanese attention to the design of education and aesthetic education has also given us a correct inspiration.

\section{ACKNOWLEDGMENT}

Funded projects: Humanities and Social Sciences key projects in Anhui Province (No. SK2017A0635)

\section{References}

1. Ezio Manzini, Joon Sang Baek, Zhong Fang translation. For social innovation and sustainable design: the hypothesis about China's "frog jumping strategy". J. Creativity and design. 22, 4 (2010)

2. Liu Xian Jie, Modern architecture theory (China Construction Industry Press, Beijing, 2008) p 167

3. Liu Xian Jie, Modern architecture theory (China Construction Industry Press, Beijing, 2008) p 212

4. Ling Jiyao, Xu heng alcohol. Art design (people's publishing house, Shanghai, 2000) p 267.

5. Gao Dan. poetic dwelling-On the beauty of Japanese Zen culture and MUJI design. J. Popular literature. 120, 13 (2014).

6. Li Liang Zhi. World history of industrial design (China Light Industry Press, Beijing, 2006) p 196

7. $\mathrm{Xu}$ Heng alcohol. Design aesthetics (Tsinghua University press, Beijing, 2006) p 70. 